\title{
How CFD supports problem analysis and solution in oil production industry
}

\author{
H. H. Al-Kayiem ${ }^{1}$, K. Y. Yin ${ }^{2}$, Z. I. Al-Hashimy ${ }^{1}$ \& I. Elena ${ }^{1}$ \\ ${ }^{1}$ Mechanical Engineering Department, \\ Universiti Teknologi PETRONAS, Malaysia \\ ${ }^{2}$ Sarawak Resource Management, Malaysia
}

\begin{abstract}
In spite of the fact that it is the most imperative and crucial industry, oil production is still facing problems which represent challenges to producers and operators. This paper presents brief highlights on CFD simulations of some problems associated with oil/water and oil/gas flows carried out by a specialized research team in Universiti Teknologi PETRONAS. Three particular problems have been modelled, simulated and analysed. The first problem is on oil/water mixture flow in the production zone in the downhole; the second is on separation of the oil/water by hydrocyclone separator in the downhole; while the third problem is on the two phase oil/gas flowing in a pipe and the resulted slug flow. For each case, the layout of the procedure of the model setup is explained, and the numerical procedure is outlined in terms of the software used, the mesh generation and its independency criteria. For each case, the validation procedure has been mentioned and in the last part of each case, some samples of results are presented and briefly discussed. Keywords: oil and gas, slug flow oil water separation, hydrocyclone, wellbore, downhole.
\end{abstract}

\section{Introduction}

With the introduction of powerful and high speed computers and advanced numerical algorithms, computational fluid dynamics (CFD) has revolutionised the industrial design, and the solution of problems existing during the operation stages. Among the three analysis techniques, theoretical, experimental and 
computational, the later one has proven to be advantageous to the others in terms of simulating and visualizing the complex problems, when fluid and heat transfer exist. The power of CFD, as a simulation and analysis technique, is evidenced in the wide adoption in the aerodynamic and propulsion design of high speed flying bodies and aerospace vehicles. In the early stage of the design of high speed fighters and missile, the designers are heavily depending on CFD techniques for the accurate prediction of the aerodynamic parameters. Consequently, the simulation and analyses by CFD has been adopted widely in various industries, all around the world. CFD analysis enables the engineers and designers to reduce or eliminate the need for expensive and complex prototypes for critical decision making through experimental investigation.

Colombo et al. [1], of SME - Italy, have published an important paper which discusses the wide use of CFD codes as a supporting tool for process and/or products development, optimization and/or innovations. They proposed a methodological approach to qualify CFD, named The Q3 approach. The approach is based on three interdependent, but related, dimensions, namely: software reliability, user knowledge and process control.

However, some review articles on the roles of CFD in specific industries have been published, which are evidencing the penetration of CFD in all the engineering and industrial scopes. Singh et al. [2] have reported the CFD roles in the Aerospace Industry in India. They concluded that CFD has emerged as an important tool in the design and analysis activities of various aerospace vehicles in India and contributing to a faster, accurate, and less expensive design process. Dassault Systèmes - SolidWorks Corp. [3], presented how SolidWorks, as a design software, integrated with CFD can optimize the design of wide range of applications in our real life without spending excess time and money in the process. They showed the power of CFD in heat transfer problems in electronic products that can be damaged easily by overheating. Designing a medical suction device for an application that needs the highest possible flow rate for a given pressure drop (suction), with limited recirculation within the device, and the most uniform velocity profile possible at the suction head has been solved by CFD simulation.

Pordal et al. [4] reported the roles of CFD in the Pharmaceutical Industry. They presented and discussed the CFD for two types of mixers, which are stirred tank reactors mixer, and a static mixer. They showed how the centrifuge separator is modified after CFD simulation, for better performance, as well as many other applications and processes, such solids handling, drying and packing.

In 2015, Raynal et al. [5] published a review paper on the applications of CFD in processes development in the oil and gas industry. The paper presents the CFD simulation of process of oil in the refineries, such as catalyst screening tool, the solvent screening tool, trickle-bed reactors, distillation column, bubble column and gas-solid flow.

In the present paper, three site problems associated with oil production in Malaysia have been simulated by the Thermofluids group in UTP using various CFD numerical techniques. The first case simulates and analyses the oil mixture flow from the perforation holes at the production zone in the downhole. The 
second case simulates and analyse the oil/water separation by hydrocyclonic separator. While the third case simulates and analyses the oil/water flow in pipelines and the associated slug flow. The selected cases are representing actual problems encountered at offshore or onshore of oil/water mixture flows.

\section{CFD simulation of the downhole}

The literature lacks information on the oil/water flow structure in the downhole. Hence an attempt has been made here to simulate the oil/water flow field in the production zone and the dumping zone in the wellbore. The simulation was conducted for a two-phase flow using ANSYS-Fluent 14 software and it was attempted to visualize the volume fraction profiles and the flow patterns in a natural downhole environment.

The well geometries and the oil/water production candidates at the downhole have been adopted from a real well in an offshore field in Malaysia. Four cases of oil-to-water mixing ratios have been considered, as 90:10, 70:30, 50:50 and 30:70, and the separator efficiency was assumed to be $90 \%$. The simulated downhole configuration is shown in fig. 1. The geometries of the two zones have been modelled using ANSYS DesignModeler. To achieve the computational model, 2D outline of the model's vertical cross-section was first sketched then revolved into a 3-D solid model.

The perforated holes on the walls, the separator inlet and outlets have been introduced later. They have been drawn at a separate plane then extruded and cut out from the solid wellbore model. The completed 3-D models for the production zone and the dumping zone are shown in fig. 2(a) and 2(b). The perforation orientation is shown in fig. 2(c).

The results illustrate the existence of great complexity of oil in water flows, reflecting the many competing processes, like turbulence, gravitational separation, droplet interaction and the shear between the two liquids and with the solid surfaces, which are occurring in the annulus.

The simulation procedure has been validated by comparing the predicted densities of the mixture obtained from the simulation against the well-established mathematical formula for the rule of mixture. Equation (3) is used to calculate the mixture density, $\rho_{\text {theory }}$; where $c_{\text {oil }}$ is the volume fraction of oil in the mixture, $\rho_{\text {oil }}$ is the density of oil and $\rho_{\text {water }}$ is the density of water. Using Equation (4), the errors from these calculations is shown in Table 1.

$$
\begin{gathered}
\rho_{\text {theory }}=c_{\text {oil }} \rho_{\text {oil }}+\left(1-c_{\text {oil }}\right) \rho_{\text {water }} \\
\text { Error }=\frac{\left|\rho_{\text {sim }}-\rho_{\text {theory }}\right|}{\rho_{\text {theory }}} \times 100
\end{gathered}
$$




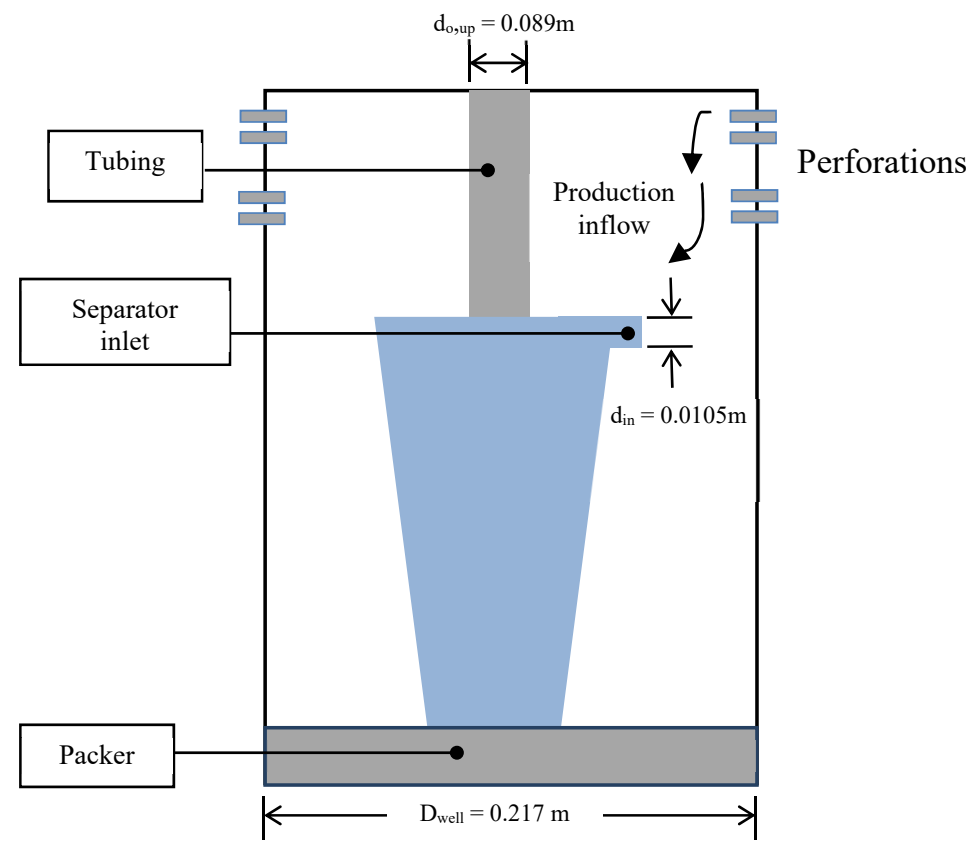

(a) the upper zone is production zone

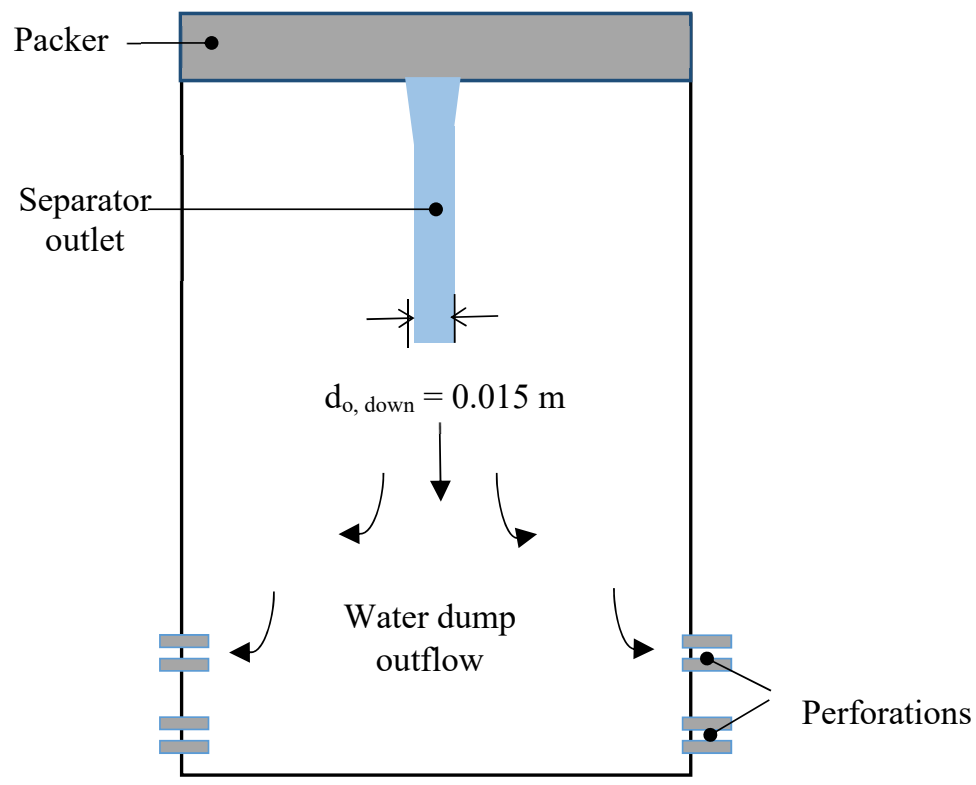

(b) Lower zone; dumping zone

Figure 1: Layout of the downhole, (a) the upper zone is production zone and (b) the lower zone dumping zone. 


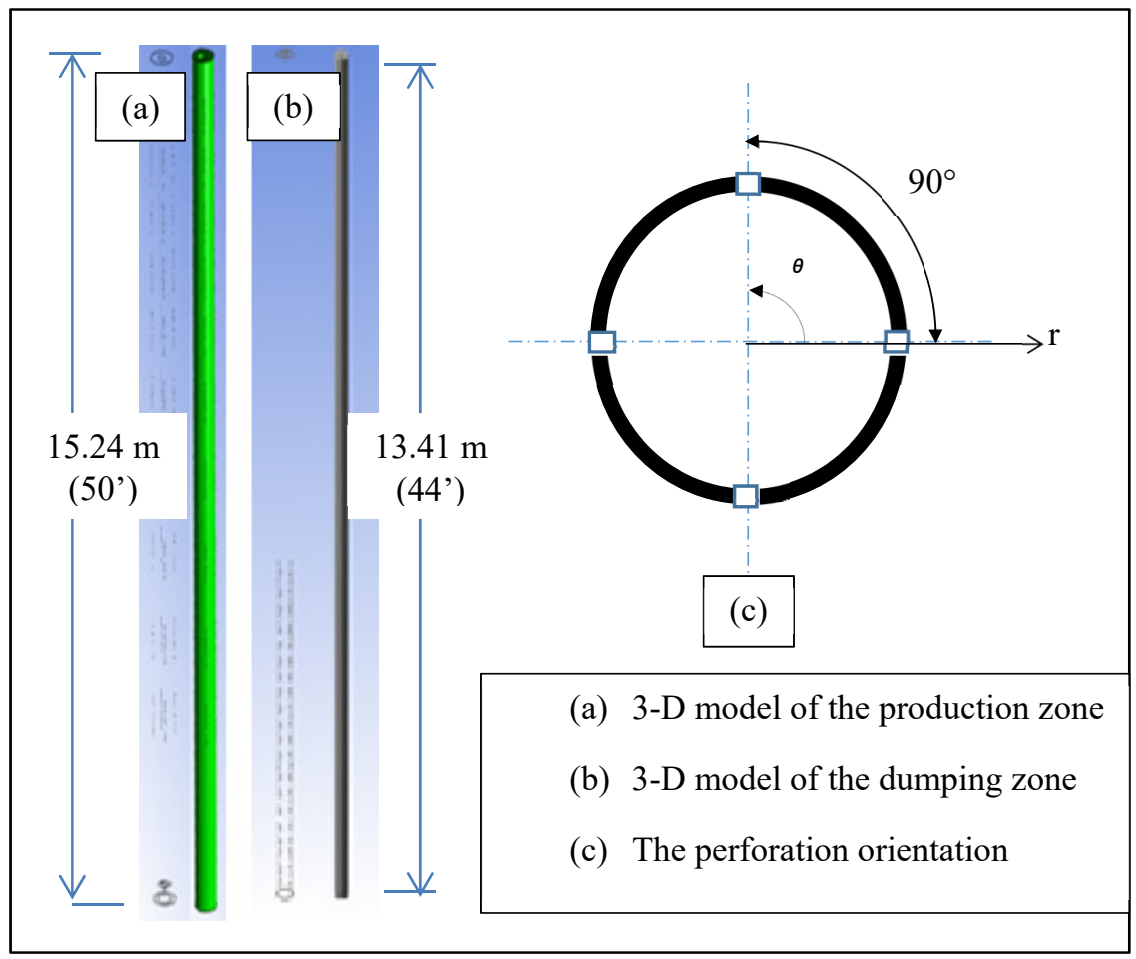

Figure 2: 3-D computational model of the downhole; (a) 3-D model of the production zone; (b) 3-D model of the dumping zone; (c) The perforation orientation.

Table 1: Validation of the procedure by comparison of predicted densities with role of mixtures.

\begin{tabular}{lcccc}
\hline Zone & $\begin{array}{c}\text { Oil } \\
\text { content }\end{array}$ & $\begin{array}{c}\text { Calculated } \\
\text { density, } \\
\boldsymbol{\rho}_{\text {theory }}\end{array}$ & $\begin{array}{c}\text { Predicted } \\
\text { density by } \\
\text { simulation, } \\
\boldsymbol{\rho}_{\text {sim }}\end{array}$ & Error \\
\hline Production & $30 \%$ & 952.00 & 961.58 & $1.0 \%$ \\
zone & $90 \%$ & 856.00 & 876.40 & $2.4 \%$ \\
\hline Dumping & $5 \%$ & 992.00 & 990.40 & $0.2 \%$ \\
\cline { 2 - 5 } zone & $50 \%$ & 920.00 & 902.60 & $1.9 \%$ \\
\hline
\end{tabular}

In the zone before the separator, the production zone, distribution of the oil volume fraction depends highly on the mean oil volume fraction and the vertical length of the zone without perforations. The contour results, in fig. 3, obtained from the simulation showed that the phases are mixing, and achieve uniform distribution as the flow proceeds down the channel. 

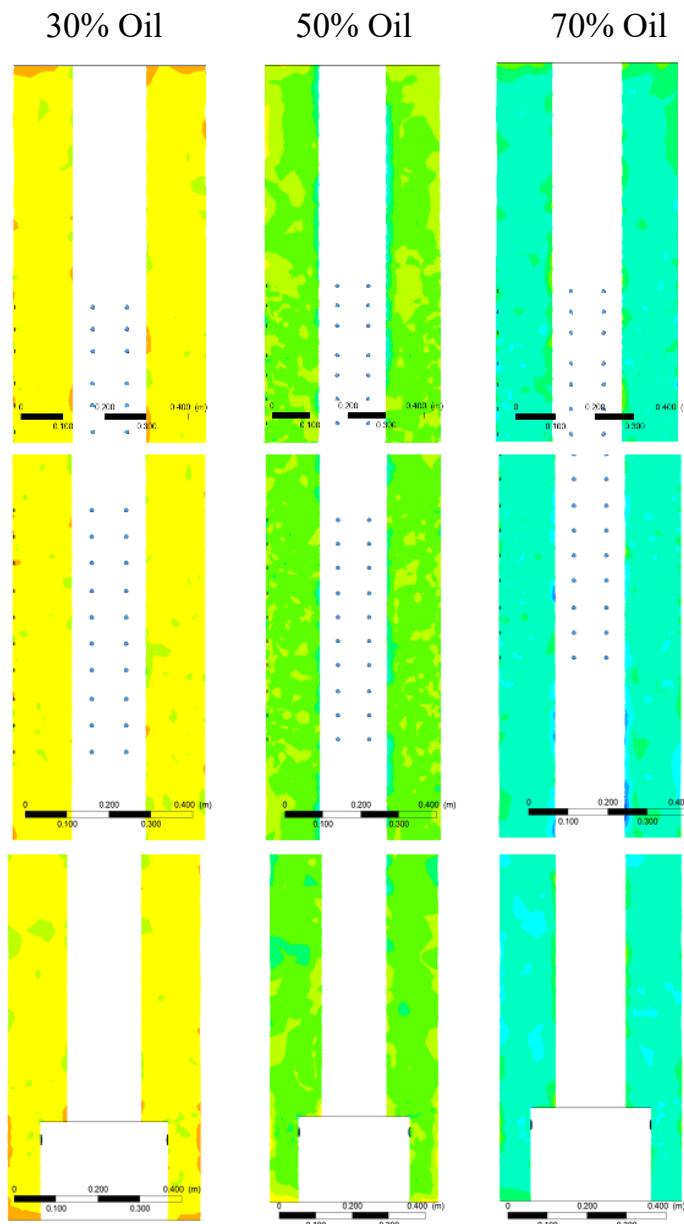

$90 \%$ Oil
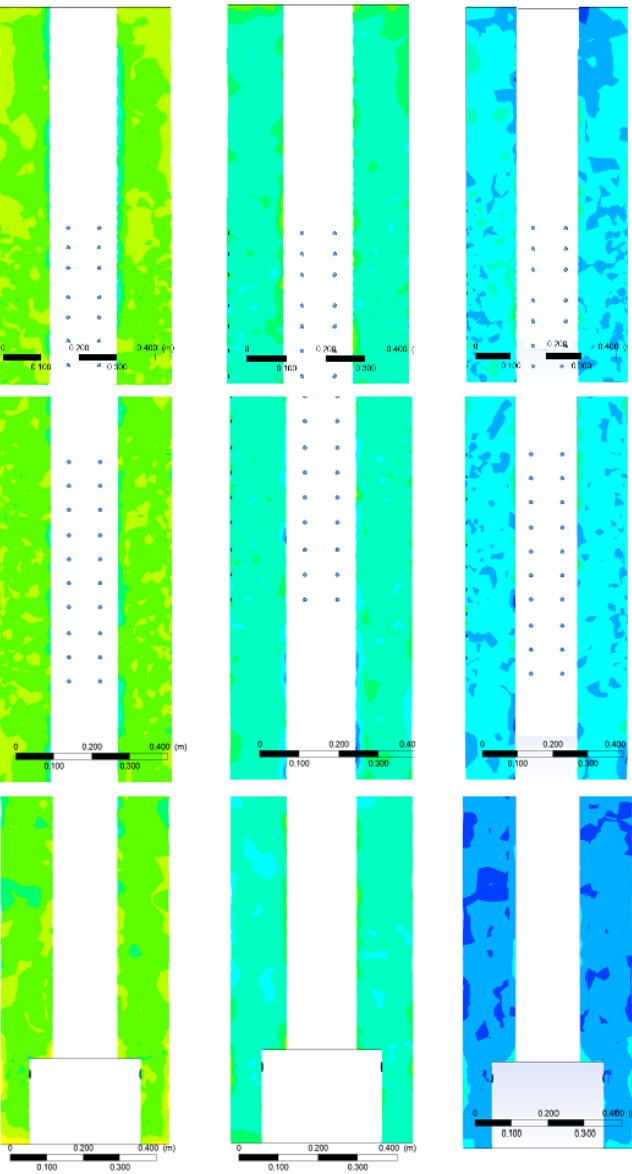

Density $\left[\mathrm{kg} \mathrm{m}^{-3}\right]$

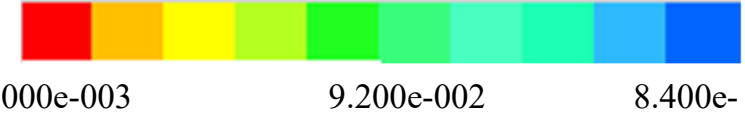

Figure 3: The predicted density distribution of oil inside the wellbore at different oil contents in the production zone.

\section{CFD simulation of the liquid-liquid hydrocyclone separator (LLHC)}

The consequences of increased water in oil production is impacting considerably on high operating expenses and produced water disposal, increasing in environmental risks. It also requires additional requirement for produced water lifting. Water production can also limit the well production life via fines 
migrations and high water production inhibits oil production to production tubing, hence causing low recovery at oil layer in the reservoir.

The above mentioned consequences have encouraged the industry to consider solutions to minimize the impact of production of unwanted water in the wells via the development of Downhole Oil-Water Separation (DOWS) technologies. DOWS is a hydrocyclone-based system for downhole separation of produced oil and water and subsequent disposal of the produced water by reinjection within the same wellbore but at different location using electric submersible pump. It has been successfully applied in a number of onshore wells, for example Alberta Canada, France, North Sea and China (Bangash [6]). However, based on lessons learned from onshore and offshore installations, the use of DOWS in offshore is limited due to its complex apparatus set up, space limitation for power generation and difficulty to re-enter well for troubleshooting.

An attempt to simulate the downhole de-oiling is presented in this paper using the hydrocyclone separation technology. Hydrocyclone separators are widely used in the industry for solid particles separation from liquids and gases. CFD has been adopted to quantitatively narrow down different flow and operational envelope of the said separation performance. With the development of CFD, it is possible to computationally assess the performance of the hydrocyclone and make design alteration for optimization purpose prior to implementation of costly experimental investigation. The hydrocyclone was modelled and simulated using ANSYSFluent 14 commercial software to study the effect of separation efficiency versus inlet velocities, inlet/outlet pressure differential, and particle traveling distant for swirling

However, for LLHC separation, the process is highly complicated due to the close densities and viscosities of the liquids. As for the oil/water, the average properties are $1000 \mathrm{~kg} / \mathrm{m}^{3}$ and $850 \mathrm{~kg} / \mathrm{m}^{3}$ densities of water and oil, respectively and $0.00097 \mathrm{~kg} / \mathrm{m}-\mathrm{s}$ and $0.00045 \mathrm{~kg} / \mathrm{m}-\mathrm{s}$ viscosities of water and oil, respectively. The outline of the simulated LLHC are shown in fig. 4 , based on the reference dimension of $\mathrm{D}=60 \mathrm{~mm}$.

Dimensions of this standard hydrocyclone with dual tangential inlet have been adopted in the present study, as it has been widely reported for investigation by several researchers (Gomez [7], Yasser et al. [8]).

Assuming isothermal and steady state condition, the inlet boundary conditions assumed an inflow with a constant velocity of $2 \mathrm{~m} / \mathrm{s}$ with pressure at inlet set at 90 psi and outlet underflow at 63 psi as per Gomez [7]. This model consisted of 60288 cells as shown in fig. 5 .

The primary phase is assumed to be water with a density of $1000 \mathrm{~kg} / \mathrm{m}^{3}$ and a viscosity value of $0.97 \mathrm{cP}$, Inert liquid spherical particles, which is oil in this case, is assumed with density and viscosity of $840 \mathrm{~kg} / \mathrm{m}^{3}$ and $0.45 \mathrm{cP}$ respectively. The oil droplet sizes are ranging from $2.3 \mu \mathrm{m}$ to $200 \mu \mathrm{m}$, hence the mean drop size is $51 \mu \mathrm{m}$. In general, larger droplets move faster and increase cyclone efficiency (Yasser et al. [8]). The stated model was solved using three-dimensional unstructured hexahedral. In order to capture the reversed flow at the hydrocyclone, block structured mesh is generated using ANSYS ICEM workbench meshing. The resulted mesh criterion of the LLHC is shown in fig. 5. 


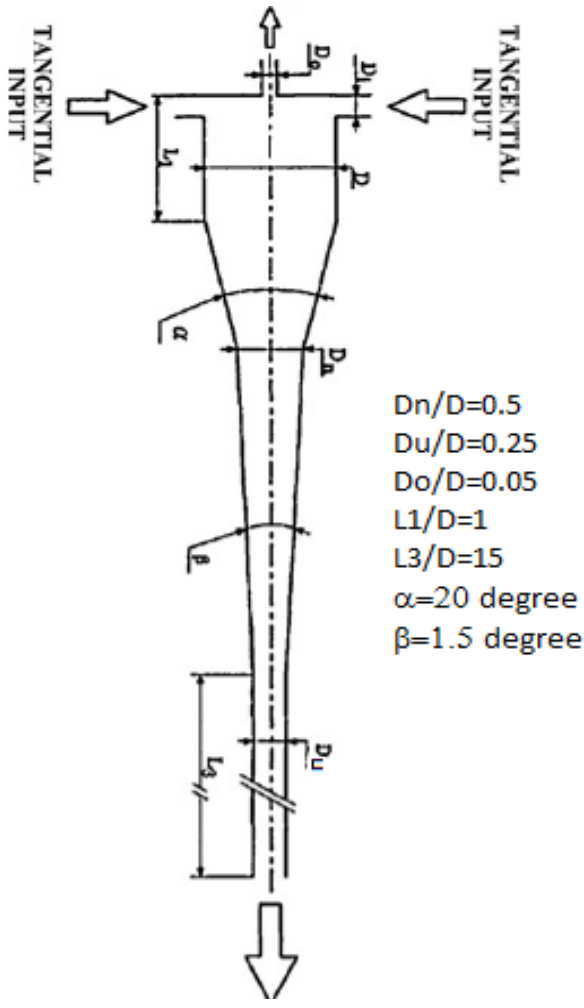

Figure 4: $\quad$ Outlines of the hydrocyclone model [7].

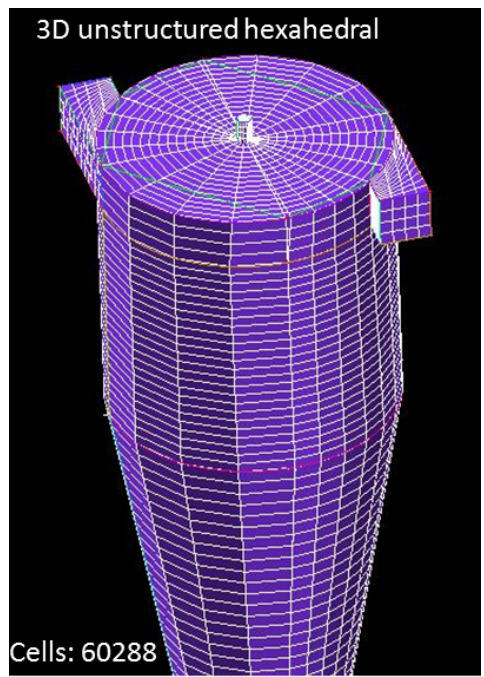

Figure 5: Meshed hydrocyclone model with two inlets. 
Discrete Phase Modelling (DPM) technique was adopted to mimic the particle separation behaviour using Lagrangian approach. This method tracked the path of individual particles through the fluid, based on force balance on individual particle. To characterize the fluid dynamics of the hydrocyclone, the key component is the turbulence model. Simulations with the $k-\varepsilon$ Standard Turbulence model, Renormalization Group (RNG), Reynolds Stress Model (RSM) or superior models as LES have been commonly studied by various researchers. The $k-\varepsilon$ Realizable Turbulence model was shown to have the capability of reproducing complex swirling flows, reaching transitory oscillatory solutions (Abdus et al. [9]).

Separation efficiency is defined as oil volume fraction at overflow over the oil volume fraction at inlet. Fig. 6 illustrated the tangential flow field in a hydrocyclone numerically. As depicted in the velocity profile, the mixtures are tangentially injected into the hydrocyclone through the horizontal inlet and resulted in swirling motion inside the conical part. Lighter fluid is separated through overflow outlet while heavier fluid discharged through underflow outlet due to the effect of centrifugal force. Fig. 6, also, shows that the vortex is in helical twisted cylinder form. It is not completely symmetrical in the axially geometry. It is also noted that low velocity zone portraying low velocity fluid concentrating at the central region due to high swirling motion.

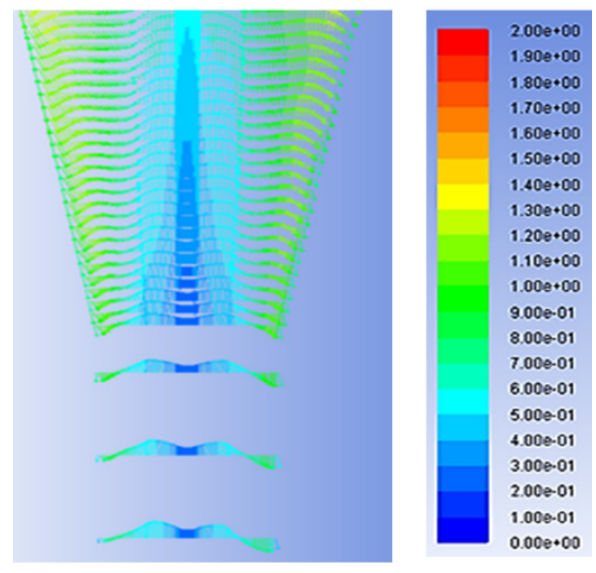

Figure 6: Velocity vectors colour by velocity magnitude.

The influence of the velocity at the inlet on the separation performance is predicted and presented in fig. 7. The pressure at inlet, as operation condition, has been considered as in the field data equal to $620.532 \mathrm{kPa}$. The pressure at the exit in the underflow is $434.372 \mathrm{kPa}$. It is clear that lower velocity leads to higher separation efficiency. However, it is not the case at the downhole where the production flow rate is not controllable parameter. 


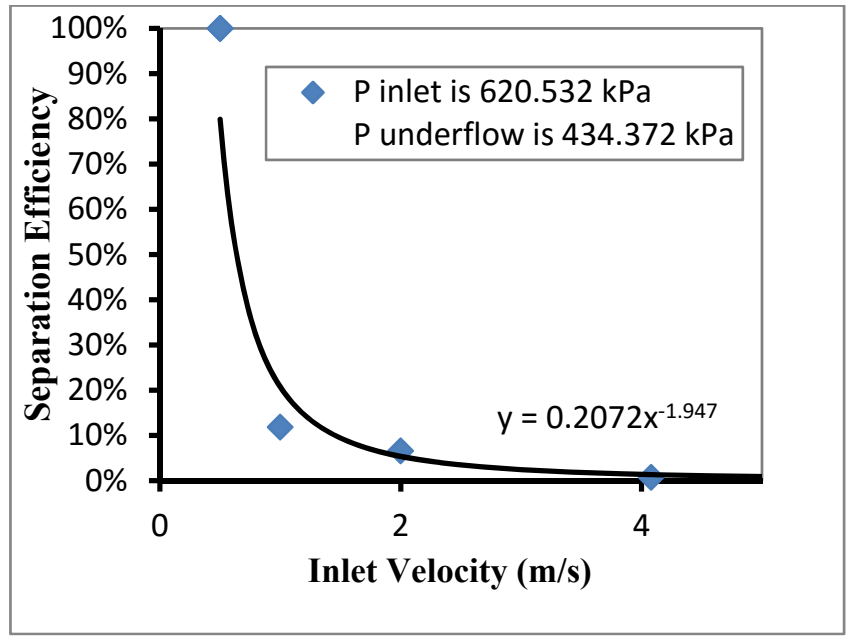

Figure 7: Influence of the inlet velocity on the separation performance.

\section{CFD simulation of oil/gas slug flow in pipelines}

Once pumped to the surface and transported through pipelines, the air dissolved in the oil starts to release as bubbles. Due to release of pressure, the bubbles start to expand and merge, and ending with formation of slug flow. The two phase air/oil or gas/oil slug flow in the pipelines cause large unstable pressure impact on the interior surface of the pipelines. The slug flow has been simulated and the impact of the pressure force fluctuation on the pipe has been predicted, and presented.

Slug flow is the predominant flow regime which is usually characterized by alternating flow of liquid slugs and gas pockets (Perez [10]). Slug flow has inherent unsteadiness which gives irregular output in term of liquid and gas at the multiphase system outlet. These irregularities in the output fluid supply cause several issues for designers and operators of the two-phase system. Also, the pressure drop for the slug flow is substantially higher than in the other flow regimes (Abdulkadir [11]). Additionally, for the systems with large capacity in the industry, the slug liquid can grow longer and possess considerable momentum which induces cyclic forces on the piping system and consequently cause severe damages.

Al-Hashimy et al. [12] studied and reported the slug implication on the pipe wall by predicting the pressure variation using CFD technique. They concluded that STAR CCM+ software is adequate to simulate complicated flows like the slug flow in horizontal pipe.

In this study, a structured hexahedral grid, in STAR CCM+ is more suitable compared to ANSYS CFD. It is experienced that STAR $\mathrm{CCM}^{+}$provides more control to obtain a fine cross sectional mesh without the need to have longitudinal one, which help the solution process to converge faster. The fluids domain was considered non symmetrical flow field. The final mesh adopted to perform the full 
3D volume simulations was divided into 156000 hexahedral cells. A number of 260 grid cells were used in a cross-section and 350 grid cells in a longitudinal section, as illustrated in fig. 8 .

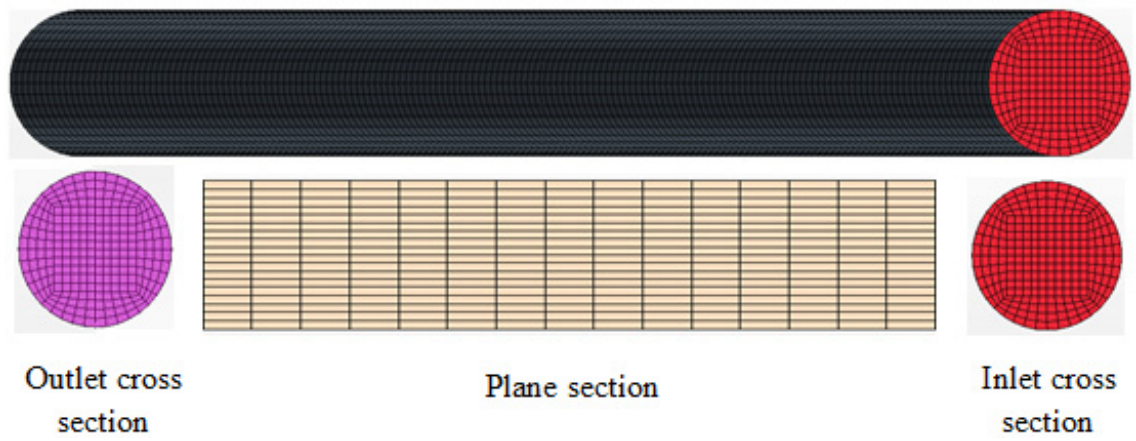

Figure 8: $2 \mathrm{~m}$ pipe segment conveying oil/gas two phase flow.

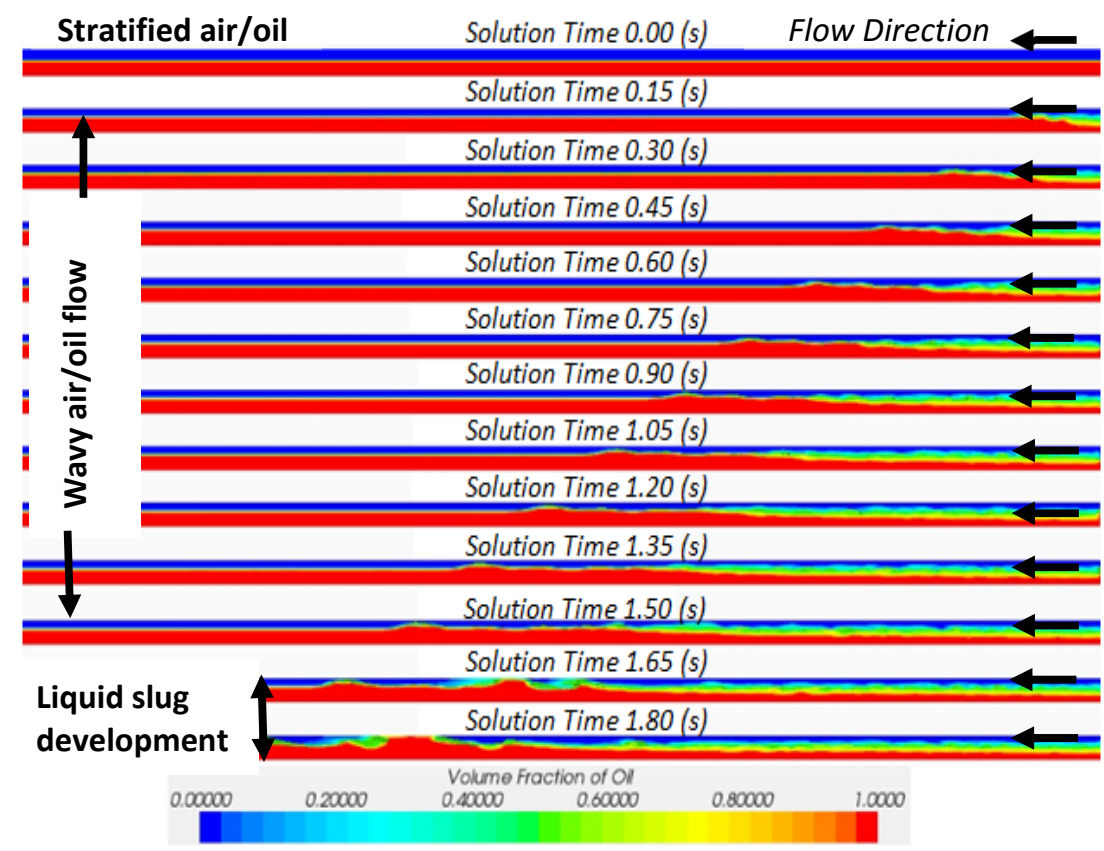

Figure 9: Development of the slug with time in oil/gas flow in horizontal pipe.

The simulation was executed under boundary conditions with superficial velocities of $U_{S O}=1.0, U_{S G}=2.443 \mathrm{~m} / \mathrm{s}$ for oil and air, respectively. Fig. 9 illustrates that during the first 1.6 seconds in the simulation, the predicted flow 
profile was depicted as a stratified two-phase flow, in which the upper part was occupied by air and the lower part was occupied by oil due to the gravitational effect. Additionally, because of the sinusoidal perturbation at the inlet, large waves were initiated. These waves are developed with time and formed the first unstable slug at $\mathrm{t}=1.80 \mathrm{~s}$. In case of air-water flow, the slug initiation was found at time $1.5 \mathrm{sec}$ which is faster from the air-oil. The density of the oil is lower than the water, which means higher momentum is required to push the oil for higher holdup accordingly the initiation of the slug in the water-air flow is earlier than the oil-air flow under the same boundary conditions

Due to lower coalescence forces in the air-oil flow, the mean liquid slug length for the air-oil, found to be $L_{S}=0.413 \mathrm{~m}$, was $10 \%$ less than in the air-water flow. The high viscosity and scooping process are the main reasons for the weak coalescence and high breakup intensity for the oil slug. Hence, it was observed that the air-oil slug split into shorter slugs due to the scooping process in which it entrained large air pockets inside the slug body.

\section{Conclusions}

CFD roles on modelling and simulating of three different cases from the production sites have been presented in this paper. It could be concluded that the CFD is a powerful tool to visualize the real fluids situation at various flow conditions, as mixture of oil/water, or two phase as oil/gas flow. The three simulated cases and analysed cases have come out with useful conclusions to the producers and operators, and may be summarized as:

In the oil wells, with production in the upper zone, a high complex oil in water flows has been realized. That is reflecting the existence of many competing processes, like turbulence, gravitational separation, droplet interaction and the shear between the two liquids and with the solid surfaces.

In the oil/water separation by double cone Hydrocyclones, the vortex is helical twisted cylinder and not completely an axially geometrical symmetry. It is also noted that low velocity zone portraying low velocity fluid concentrating at the central due to high swirling motion. The simulation with various inlet velocity is indicating that lower inlet velocity leads to higher separation efficiency.

Simulation of air-oil slug flow, the mean liquid slug length, which was found to be $\mathrm{LS}=0.413 \mathrm{~m}$, was $10 \%$ less than in the case of air-water flow. The high viscosity and scooping process are the main reasons for the weak coalescence and high breakup intensity for the oil slug.

\section{Acknowledgement}

The authors acknowledge Universiti Teknologi PETRONAS for providing the financial support under YUTP-FRG 015-3AA-A34 and 015-3AA-A72. 


\section{References}

[1] E. Colombo, F. Inzoli, R. Mereu. A methodology for qualifying industrial CFD: The Q3 approach and the role of a protocol. Computers \& Fluids 54, pp. 56-66, 2012.

[2] K. P. Singh, J. S. Mathur, V. Ashok, and Debasis Chakraborty. Computational Fluid Dynamics in Aerospace Industry in India. Defence Science Journal, Vol. 60, No. 6, pp. 639-652, 2010.

[3] The role of CFD in real life designs. Dassault Systèmes SolidWorks Corp. https://www.solidworks.com/sw/docs/CFD_2010_ENG_FINAL.pdf. (Retrieved March 2016).

[4] H. S. Pordal, C. J. Matice, and T.J. Fry. The Role of Computational Fluid Dynamics in the Pharmaceutical Industry, Pharmaceutical Technology. pp. 27-79, 2002.

[5] L. Raynal, F. Augier, F. Bazer-Bachi, Y. Haroun and C. Pereira da Fonte. CFD Applied to Process Development in the Oil and Gas Industry - A Review. Oil \& Gas Science and Technology - Rev. IFP Energies nouvelles, 2015. DOI: $10.2516 /$ ogst $/ 2015019$.

[6] Y. K. Bangash. Downhole Oil Water Separation (DOWS) Systems in HighVolume/High HP Application. SPE Wood Group ESP, Inc. SPE 81123, 2003.

[7] C. H. Gomez. Oil-Water Separation in Liquid-Liquid Hydrocyclones (LLHC) Experiment and Modelling, University of Tulsa, Tulsa, 2001.

[8] K. B. Yasser, R. B Michael, E. C. Stephen, Downhole Rotary Water Separation System, Wood Group ESP Inc., Oklahoma City, US. US 6547003 B1. 2000.

[9] S. Abdus, M. I. Ghulam, L. B. James. Practical Enhanced Reservoir Engineering: Assisted with Simulation Software. PennWell Corporation, Tulsa, Oklahoma, USA, 2007.

[10] V. Hernandez Perez. Gas-liquid two-phase flow in inclined pipes, $\mathrm{PhD}$ thesis, University of Nottingham, 2008.

[11] M. Abdulkadir. Experimental and computational fluid dynamics (CFD) studies of gas-liquid flow in bends, $\mathrm{PhD}$ thesis, University of Nottingham, 2011.

[12] Al-Hashimy, Z. I., H. H. Al-Kayiem, Z. K. Kadhim, and A. O. Mohmmed. Numerical simulation and pressure drop prediction of slug flow in oil/gas pipelines. Computational Methods in Multiphase Flow VIII, WIT Transactions on Engineering Sciences 89, pp. 57-65, 2015. DOI: 10.2495/MPF150051. 